\title{
Electron Microscopy Study of Mineral Colloids in the Ground Water Near Nevada Test Site
}

\author{
L. P. You , L.M. Wang*, S. Utsunomiya*, R.C. Ewing* , A.B. Kersting ${ }^{* *}$ and P. Zhao ${ }^{* *}$ \\ *Department of Nuclear Engineering and Radiological Science, University of Michigan, Ann Arbor, \\ MI 48109-2104 \\ ** Lawrence Livermore National Laboratory, PO Box 808, L-231, Livermore CA 94550
}

The colloidal groundwater migration has played an important role in transporting the radionuclide through geosphere. [1-3] Models that either predict limited transport or do not allow for colloidfacilitated transport may thus significantly underestimate the extent of radionuclide migration. Our ability to develop reliable subsurface contaminant transport models and mitigation strategies is limited, in part, by our understanding of the geochemical mechanisms that operate at the mineral water interface. Mineral colloids are ubiquitous in groundwater and have the potential to enhance transport of contaminants that strongly sorb to the solid phase. Investigations aimed at understanding the mechanisms controlling radionuclide contaminant transport in field settings are routinely hampered by the low concentrations of radionuclides detected in groundwater, thus limiting the spectroscopic techniques available for investigation.

We have overcome this limitation by taking advantage of the newly developed technology of Zcontrast imaging with high angle annular dark field (HAADF) in scanning transmission electron microscopy (STEM) mode [2] to detect and identify nanoparticles of high local mass (Z) (e.g. actinides) at very low natural abundances in groundwater colloids. Combined with energy dispersive $\mathrm{x}$-ray spectroscopy (EDS), we have been able to detect nanoscale radionuclide colloids sorbed onto silicate colloids in groundwater downgradient of underground nuclear tests at the Nevada Test Site (NTS). As shown in Fig. 1, nanoscale colloids containing U, Au, Ag, Zr, Ba, Ce, Fe are observed in the sample filtered from the ground water. These particles have a diameter range between 10-100 nm and are absorbed on the surface of the $(\mathrm{Ca}, \mathrm{K}, \mathrm{Si}, \mathrm{Al}, \mathrm{S}, \mathrm{Na})$-rich silicate phases. Furthermore, high resolution TEM (HRTEM), nanobeam electron diffraction and EDS have also been used for the identification of the mineral colloids and the sorbed nanoparticles. Mineral phases such as smectite, illite, calcite, coffinite, monazite, zeolite, rutile, as well as thorium phosphate have been identified in the sample. Fig. 2 shows a group of Au nanoparticles in the same sample. These Au particles have a diameter range between $2-10 \mathrm{~nm}$. They seem to be embedded in a silicate phase and appear in the vicinity of a Ru-rich phase. Our results demonstrate that the overwhelming majority of the lowsolubility radionuclides are associated with the colloidal fraction of the groundwater.

\section{References}

[1] A.B. Kersting, et al., Nature 397, (1999) 56.

[2] B.W. Buddemeier, et al., Appl. Geochem 3, (1988) 535.

[3] W. R. Penrose, et al., Environ. Sci. Technol 24, (1990) 228.

[4] E.M. James and N.D. Browning, Ultramicroscopy 78, (1999) 125.

[5] Electron microscopy was conducted with a JEM 2010F microscope at the Electron Microbeam Analysis Laboratory (EMAL) at the University of Michigan. 


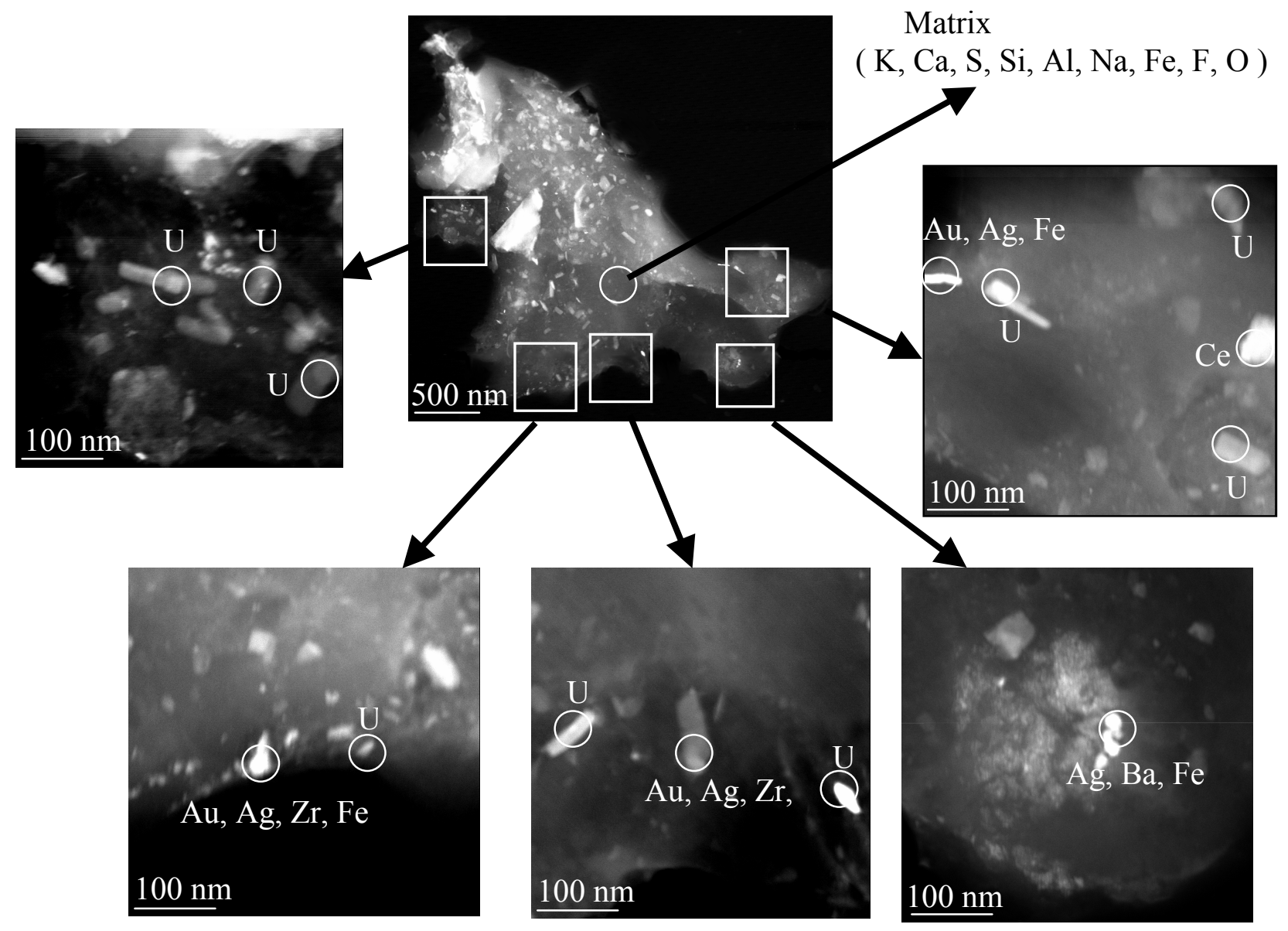

FIG. 1. HAADF STEM image showing the distribution of $\mathrm{U}, \mathrm{Au}, \mathrm{Ag}, \mathrm{Zr}, \mathrm{Ba}, \mathrm{Ce}, \mathrm{Fe}$ containing colloids in a sample filtered out from the ground water near the Nevada Test Sites.
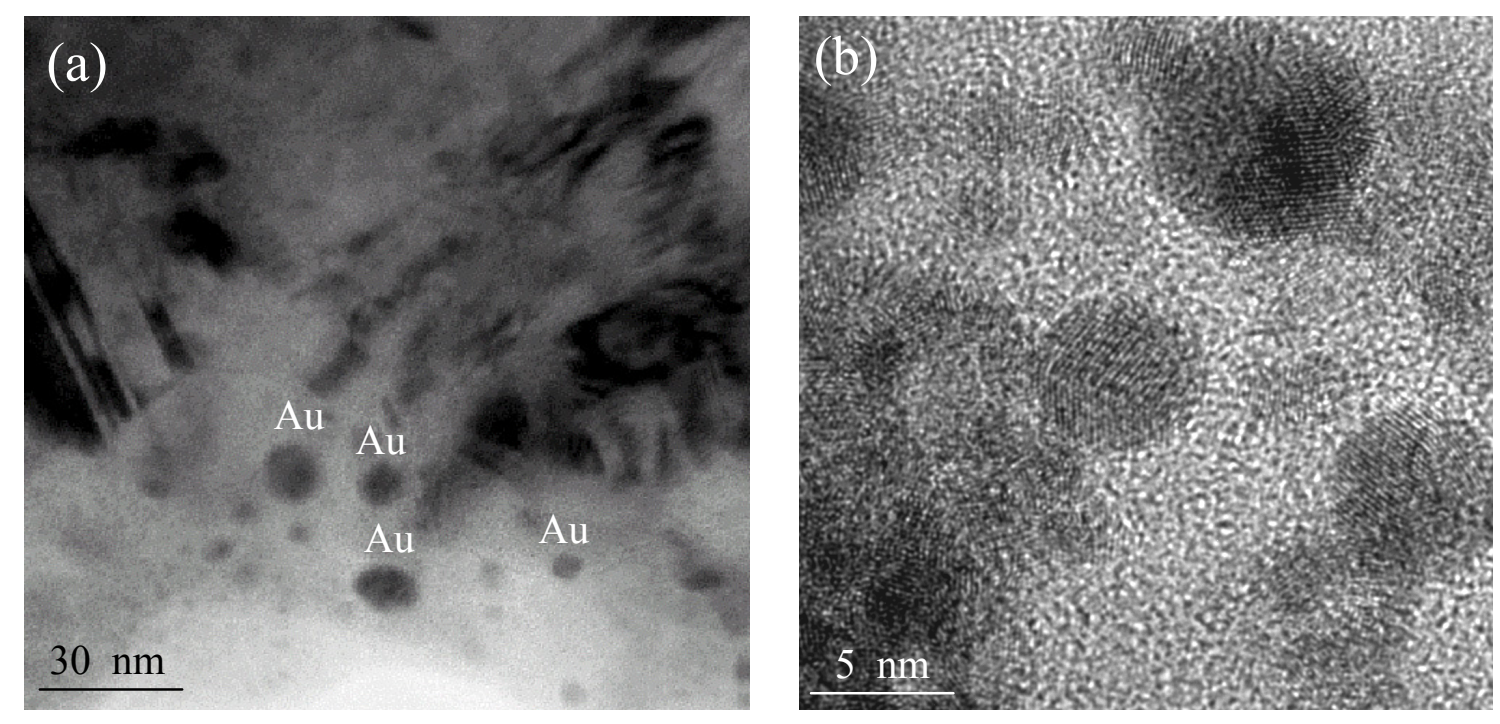

FIG. 2. (a) TEM image and (b) HRTEM image of Au nanoparticles in a sample filtered out from the ground water near the Nevada Test Sites. 